\title{
Test yourself question: a 19-year-old male presents with progressive distal lower limb pain
}

\author{
Ramanan Rajakulasingam ${ }^{1}$ (i) $\cdot$ Miriam Ficial $^{2} \cdot$ Asif Saifuddin $^{1}$
}

Received: 2 April 2021 / Revised: 14 June 2021 / Accepted: 24 June 2021 / Published online: 5 July 2021

(c) Crown 2021

\section{Test yourself question}

A 19-year-old male presenting with a 3-month history of progressive distal lower limb pain. Previous fracture 4-years earlier (radiograph not available) was treated in a cast (Figs. 1, 2, 3, and 4).

The diagnosis can be found at https://doi.org/10.1007/s00256-02103855-z

Ramanan Rajakulasingam

Ramanan.rajakulasingam1@nhs.net

Miriam Ficial

miriam.ficial@nhs.net

Asif Saifuddin

Asif.saiffudin@nhs.net

1 Department of Radiology, Royal National Orthopaedic

Hospital, Brockley Hill, Stanmore HA7 4LP, Middlesex, UK

2 Department of Cellular and Molecular Pathology,

Royal National Orthopaedic Hospital, Brockley Hill,

Stanmore HA7 4LP, Middlesex, UK 
Fig. 1 AP radiograph of the right distal lower limb

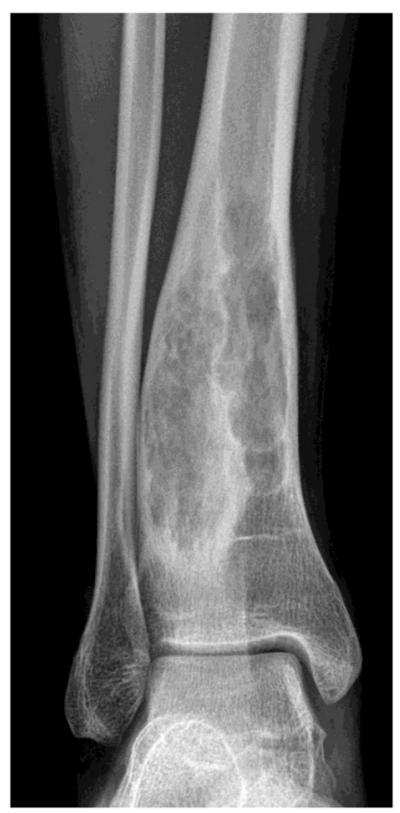

Fig. 2 (a) Coronal T1W TSE and (b) axial PDW FSWE MR images of the distal right lower limb

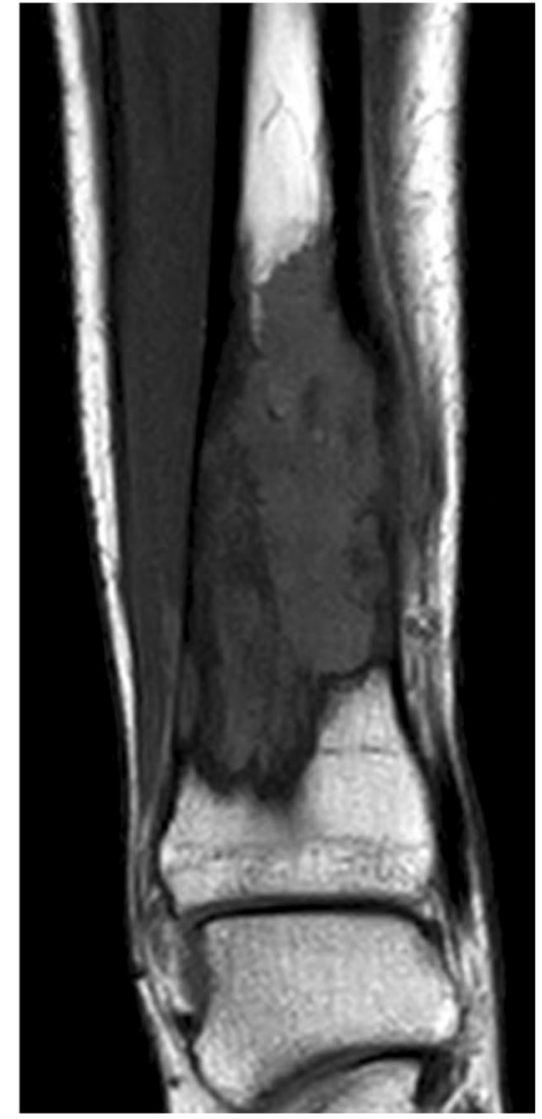

a

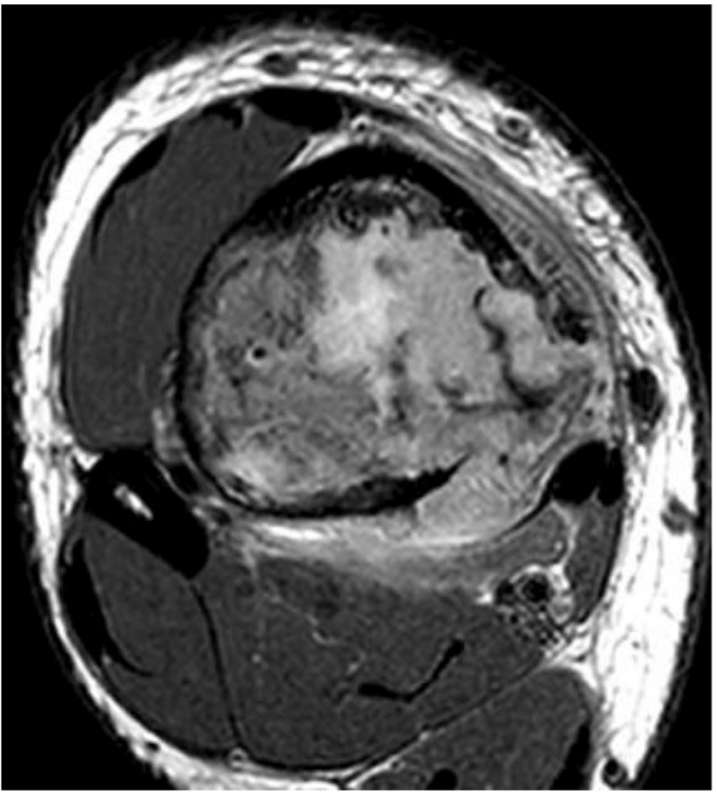

b 
Fig. 3 Coronal CT MPR of the distal right lower limb
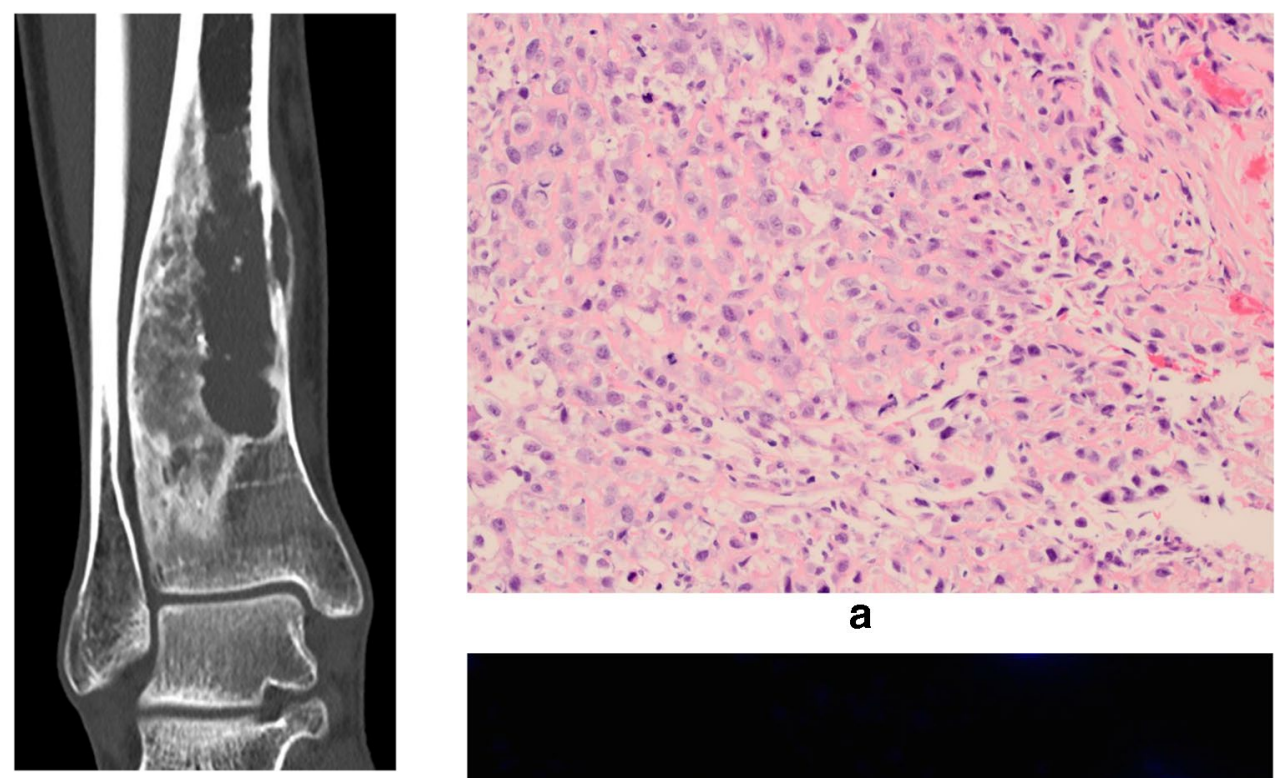

a

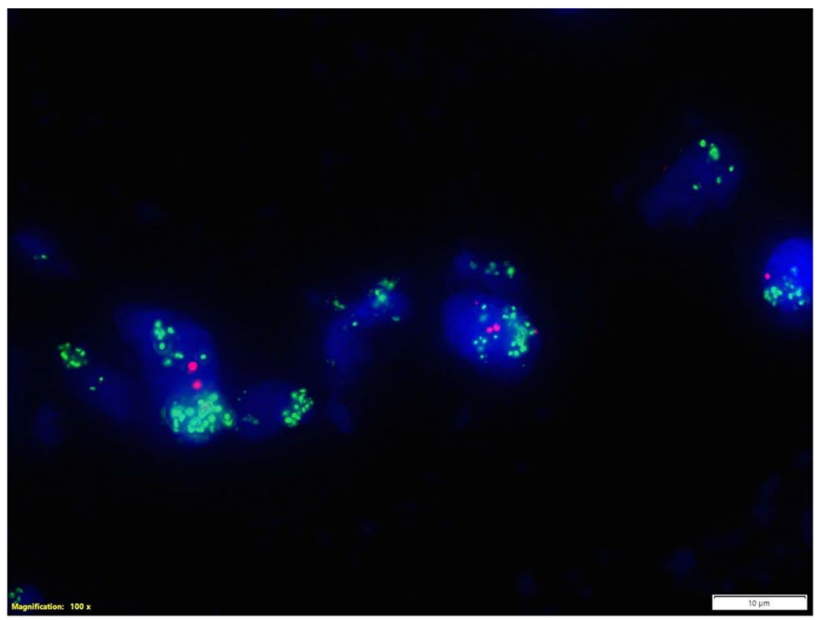

b

Fig. 4 Needle biopsy. (a) H \& E section (x10 magnification). (b) Fluorescent In situ hybridization (FISH) image (x100 magnification) for MDM2

Publisher's note Springer Nature remains neutral with regard to jurisdictional claims in published maps and institutional affiliations. 